\title{
De cuerpos subjetivados e imágenes artistizadas: la lógica biopolítica de la historia del arte
}

\author{
Santos Rojas Ogáyar \\ Universidad de Granada \\ santosrojasogayar@gmail.com
}

RESUMEN: En su escrito Sobre las ruinas del museo, Douglas Crimp planteó la necesidad de abrir un capítulo olvidado por parte de la crítica hacia las entrañas de la modernidad. Foucault había diseccionado buena parte de los saberes e instituciones del nuevo teatro epistemológico, pero una disciplina evitó su operación quirúrgica: la historia del arte. Concebida como una histórica secuencia de paradigmas interrelacionados o como un saber científico y puramente taxonómico, la historia del arte funciona como el artefacto discursivo que produce y legitima una nueva verdad para las imágenes. Por ello, el texto plantea la síntesis de una serie de hipótesis que animan a repensar la disciplina como hermana contemporánea de dispositivos disciplinarios como la criminalidad, la enfermedad mental o la sexualidad, con el fin de integrarla en el nuevo régimen somatopolítico de las imágenes y en el epicentro de las nuevas técnicas de poder.

PALABRAS CLAVE: Historia del arte; Disciplina; Imagen; Epistemología; Biopolítica.

\section{Subjetive Bodies and Artistic Images: the Biopolitical Logic of Art History}

ABSTRACT: In his essay On the ruins of the museum, Douglas Crimp proposed the need for critics to open a forgotten chapter about the entrails of modernity. Foucault had dissected much of the knowledge and institutions of the new epistemological theatre, but one discipline had avoided his surgical procedure: art history. Conceived as a historical sequence of interrelated paradigms or as a scientific and purely taxonomic knowledge, art history functions as the discursive artifact that produces and legitimizes a new truth for images. Therefore, the text presents the synthesis of a series of hypotheses that encourage us to rethink the discipline as a modern kinswoman of disciplinary devices such as crime, mental disease or sexuality in order to integrate it into the new somatic-political regime of images and the epicenter of the new power techniques.

KEYWORDS: Art History; Discipline; Image; Epistemology; Biopolitics.

Recibido: 25 de febrero de 2020 / Aceptado: 16 de junio de 2020.

\begin{abstract}
-iAh, ya ve, Kotecki! No hay nada como la escuela para fomentar el culto al arte. ¿Quién de nosotros sabría admirar a los grandes genios, si en la escuela no se le hubiese puesto bien en la cabeza que son grandes genios? Witold Gombrowicz, Ferdydurque
\end{abstract}

Foucault analizó las instituciones modernas de confinamiento -el manicomio, la clínica y la prisión- y sus respectivas formaciones discursivas -la locura, la enfermedad y la criminalidad-. Existe otra institución de confinamiento -el museo- y otra disciplina -la historia del arte- a la espera de un análisis arqueológico.

Douglas Crimp, Sobre las ruinas del museo

Todavía es un tema que, cuando no se trata con la boca pequeña, es directamente denostado por determinados departamentos de investigación académica. Contra toda convicción anquilosada históricamente, a pesar de los ríos de tinta de manuales

Cómo citar este artículo: ROJAS OGÁYAR, Santos, "De cuerpos subjetivados e imágenes artistizadas: la lógica biopolítica de la historia del arte», Boletín de Arte-UMA, n. ${ }^{\circ}$ 41, Departamento de Historia del Arte, Universidad de Málaga, 2020, pp. 219-226, ISSN: 0211-8483, e-ISSN: 2695-415X, DOI: http://dx.doi.org/10.24310/BoLArte.2020. v41i.8007 
que reproducen una y otra vez el relato de un ideal universal, el Arte, con mayúsculas, no es una verdad ontológica; es, tal y como han advertido los sectores críticos de la sociología del arte y la teoría institucional, un constructo articulado en un período histórico determinado, una invención que nace en focos intelectuales europeos muy concretos y que tiene un recorrido que podría terminar en cualquier momento, si no lo ha hecho ya. $Y$ es que las profundas transformaciones simbólicas, políticas y tecnológicas que se dan entre los siglos XVIII y XIX en las sociedades de Europa occidental obligan a confeccionar un nuevo escenario para el tratamiento de las imágenes, y la noción moderna de arte juega para ello un papel esencial. Pero ¿a qué metamorfosis nos estamos refiriendo?

Paul B. Preciado, en su disección de las técnicas de producción del cuerpo y la subjetividad, aboga por la necesidad de establecer lo que denomina una «genealogía política del cuerpo ${ }^{1}$, entendida como un arma político-epistemológica que nos permita "comprender cuáles y cómo han sido los procesos de construcción de las "ficciones políticas" -la identidad sexual, el género, la clase social, la raza...- que nos conforman y constituyen». Preciado divide dicha genealogía en tres etapas o, en sus propios términos, regímenes somatopolíticos:

En primer lugar, el régimen soberano, vigente hasta finales del siglo XVIII y principios del siglo XIX, se caracteriza por la invasión del cuerpo por un poder teocrático y la imposición de una verdad revelada por mandato divino. El cuerpo está sujeto a un poder de absoluta emanación teológica, personificado a nivel macro-político por la figura del rey y por el Pater Familias a nivel micro-político.

El segundo de los regímenes es el biopolítico o disciplinario, implementado sobre todo en el siglo XIX. Este es el período del nacimiento de las instituciones totales (hospital, cárcel, escuela, museo, etc.), espacios que funcionan como potentes y novedosos focos de producción de subjetividad. El cuerpo transmuta en fuerza de producción y reproducción nacional; la verdad se desvincula del ámbito teológico, por lo que el cuerpo ya no será la superficie de inscripción de un saber teocrático, sino del discurso médico-científico-jurídico. La secularización del cuerpo lleva aparejada la inscripción de un sistema dicotómico de verificación sobre el mismo: hombre/mujer, heterosexual/homosexual, etc. ${ }^{2}$

Nos emplazamos, por tanto, en una brecha cronológica conflictiva en la que la concepción occidental de cuerpos e imágenes está siendo sometida a tensiones revolucionarias y a nuevos paradigmas de comprensión y representación, un paralelismo que resulta de lo más sugerente para trabajar con diversas hipótesis. ¿Qué relación existe entre el cambio en las técnicas de producción de cuerpo y subjetividad y los cambios en la relación con las imágenes? ¿Qué implicaciones epistémicas, y consecuencias políticas sobre las imágenes mismas, tiene el nacimiento del dispositivo artístico y qué sentido cobra el nacimiento de nuevos territorios discursivos sobre el arte? Existen más vínculos de los que pudiera parecer, en la medida en que podríamos considerar a cuerpos e imágenes como superficies de inscripción sobre las que se imprimen determinadas ficciones normativizadas históricamente. De esta manera, las imágenes compartirían la característica que Foucault corroboró en los cuerpos, pues al igual que estos, conformarían un estatuto complejo en tanto instrumentos y, al mismo tiempo, efectos del poder (Benavides, 2017: 601).

Como consecuencia, el paralelo nos permite intuir una hipótesis tan vasta como atractiva: la Europa occidental de fines del siglo XVIII es el marco espaciotemporal en el que las imágenes sufren la misma metamorfosis somatopolítica que los cuerpos, y el dispositivo artístico sería la tecnología resultante de dicho proceso transformador. La disciplina de la historia del arte, en sintonía con discusiones académicas de primer orden en el debate historiográfico actual -así lo atestiguan las obras de Hans Belting o Georges Didi-Huberman-, no sería sino el paradigma epistemológico al que va asociado este dispositivo de poder ${ }^{3}$. A partir de este momento, el arte constituirá el marco que encerrará jurídica, discursiva e institucionalmente a las imágenes y objetos de significación heredados del Antiguo Régimen, los cuales pasarán de estar sometidos por un régimen soberano a formar parte del aparataje disciplinario de la modernidad. Las imágenes, que hasta entonces habían sido la expresión más fiel del poder soberano (ya fuera monárquico o religioso), se convertirán en signos de la genialidad humana, manifestaciones cuya única función es la satisfacción espiritual, ahora colectiva, del ser humano por medio de la contemplación estética; ya no serán símbolos de una verdad teológica, sino revelaciones de un saber desinteresado, expresiones de una nueva verdad disciplinaria, incluso símbolos de enaltecimiento nacional.

Por su parte, la asociación del binomio cuerpo-imagen que intuye la hipótesis es un punto de fricción recurrente en 
la antropología contemporánea de las imágenes. El propio Didi-Huberman sostiene:

La imagen reclama lo sensible, pero lo sensible implica el cuerpo, el cuerpo se agita con los gestos, los gestos vehiculan emociones, las emociones son inseparables del inconsciente, y el inconsciente implica en sí mismo un nudo de tiempos psíquicos, de manera que una sola imagen puede poner en juego o en cuestión todo el modelado del tiempo y de la historia misma, incluso de la historia política (2017: 129).

Como un triángulo de interrelaciones, la sensibilidad es reclamada por la imagen y, consecuentemente, implicada en el cuerpo. No obstante, lo que aquí visibilizamos no es tanto el caudal de conexiones entre los tres vértices como los efectos que tienen las transformaciones político-culturales del momento en tanto caldo de cultivo para la producción de un nuevo régimen de sensibilidad. Las imágenes, como se sugiere, se ven afectadas por los mismos regímenes somatopolíticos que los cuerpos. De ser esto así, el arte sería el dispositivo hermanado con sus contemporáneos -la sexualidad, la criminalidad, la locura...-, y la historia del arte no compartiría solo coincidencia cronológica con la psiquiatría, la clínica o el derecho. La brecha temporal en que nos situamos es la época del placer desinteresado, del nacimiento del sistema moderno de las Bellas Artes, de la creación del museo, del origen de la historia y la crítica de arte; es decir, la de la inauguración de un nuevo estatuto disciplinario para las imágenes, un régimen de sensibilidad cargado de ritualidades y discursos que se inscriben en las imágenes, focalizado en la gestión del nuevo gusto burgués mediante la programación de un relato legitimador. La historia del arte, por tanto, se adecua como eslabón de un engranaje complejo, producto de las permutas epistemológicas de los saberes occidentales en la transición secular de la época que nos ocupa.

Dice así Foucault:

La enfermedad mental ha estado constituida por el conjunto de lo que ha sido dicho en el grupo de todos los enunciados que la nombraban, la recortaban, la describían, la explicaban, contaban sus desarrollos, indicaban sus diversas correlaciones, la juzgaban y eventualmente le prestaban la palabra, articulando en su nombre discursos que debían pasar por ser los suyos (1991: 52).
Hagamos el ejercicio de sustituir «enfermedad mental» por «arte». La historia del arte es la encargada de la producción de dichos enunciados que nombran, recortan, describen, explican, cuentan su desarrollo, indican correlaciones, juzgan y le prestan la palabra. El arte, en sí mismo, constituye una ficción cultural que solo funciona a partir del conjunto de enunciados que la nombran; unos enunciados que se filtran discursivamente -mediante la disciplina que aquí analizamos- e institucionalmente -a través del museo-. Para ello, se construyen complejas tecnologías de discurso a modo de andamiaje para unas narrativas que no satisfacen más que las necesidades del nuevo marco político-económico para/ con las imágenes. Filtrada a través de las instituciones totales -academias y museos, principalmente- la historia del arte constituye una invención discursiva al servicio de una imposición social en el nuevo teatro ideológico ilustrado: la de una de las «trascendencias seculares de la modernidad» (Ortiz, 2009: 1), entre las que están el arte, la razón, el Estado y el sexo, entre otras.

Desde este punto de vista, podemos comprobar, cuanto menos, que la disciplina forma parte de un tejido epistemológico más complejo de lo que parece. Sus intereses, protocolos y su marco de actuación tienen poco que ver con las pretendidas características de un saber que no es meramente taxonómico y que está, como sus coetáneos, estrechamente vinculado al ejercicio del poder ${ }^{4}$. La disciplina no es la ciencia descriptiva que históricamente se ha vanagloriado de ser. Su lenguaje no se limita a describir una realidad transhistórica, sino a desarrollar los parámetros de su constructo-objeto de estudio, el arte, y a imprimir estos en determinadas imágenes y objetos ${ }^{5}$. Esta hipótesis resitúa a la historia del arte en los problemas señalados por Foucault cuando afirmaba que

Lo que explica la dificultad de las «ciencias humanas", su precariedad, su incertidumbre como ciencias, su peligrosa familiaridad con la filosofía, su mal definido apoyo en otros dominios del saber, su carácter siempre secundario y derivado, pero también su pretensión a lo universal, no es, como se dice con frecuencia, la extrema densidad de su objeto; no es el estatuto metafísico o la imborrable trascendencia del hombre del que hablan, sino más bien la complejidad de la configuración epistemológica en la que se encuentran colocadas (2006, 338). 
Dicho lo cual, una de sus cualidades fundamentales, por tanto, es la performatividad: la capacidad de producir la verdad que dice describir. Esta característica remite a la lectura que Judith Butler realiza de How to do things with words de John Langshaw Austin; de esta manera, entenderemos que «la noción de performatividad no tiene nada que ver con la forma artística de la performance» (Hantelmann, 2017: 25). Atravesadas por las tesis derridianas sobre el performativo, las argumentaciones de Butler explican con este término la capacidad que tiene el lenguaje para producir la realidad que a priori dice describir, habilidad inherente al régimen discursivo de la historia del arte en su confección. Esta, a pesar de reivindicar su papel puramente taxonómico y erigirse como ciencia dedicada al análisis de la condición y evolución de las imágenes, produce y gestiona el objeto de estudio del que simultáneamente se distancia. La historia del arte, coincidiendo con López Rubiño,

[...] no solo legitima y monumentaliza una determinada selección de objetos, sino que además naturaliza la idea que estos objetos supuestamente ejemplifican. Esta maniobra se puede identificar en uno de los postulados fundamentales de la construcción de la Historia del Arte (i. e. del relato de la historia del Arte), y radica en el hecho de hacer coincidir el origen (inicio) del Arte con el origen del Hombre: el Arte como indicador esencial y signo característico de lo específicamente humano, i. e. el Arte como prueba de inicio de la humanidad. De este modo, se asume que la historia del Arte comienza a la par y se relata en paralelo a la historia del Hombre (2015: 193-194).

Así, la relación que pudiera existir entre las pinturas de Altamira, las catedrales góticas europeas y la pintura del romanticismo alemán tiene más que ver con un juego disciplinario impreso sobre estas manifestaciones culturales en tanto superficies de inscripción. La historia del arte es el resultado de esta ecuación discursiva, instaura un régimen disciplinario que responde a necesidades muy concretas del ideario de la modernidad ilustrada: no solo constituir un marco relacional con las imágenes, sino buscar imbricaciones políticas por las que estas puedan canalizar la memoria del sujeto burgués. En este sentido, la disciplina es una tecnología más al servicio de la producción de subjetividad dominante, una de las ficciones macro-narrativas más potentes del tablero epistemológico de la modernidad y, por tanto, uno de los tentáculos de la ideología cultural del capitalismo contemporáneo.

Este debería ser, consideramos, el punto de partida de cualquier relectura crítica de la historia del arte como disciplina cuyas raíces resulta necesario encuadrar, es decir, localizar en el marco espaciotemporal de «las transformaciones de la economía medieval del siglo XV que darán paso a las economías industriales, a los Estados-Nación y a los regímenes de saber científico-técnico occidentales» (Preciado, 2008: 112). Cuanto menos, la hipótesis contribuiría al cuestionamiento de ese tono de certeza ${ }^{6}$ (Didi-Huberman, 1990: 12) incomprensible para una disciplina que, como tecnología moderna de verificación, presenta innumerables equívocos y fragilidades.

Tal y como apunta Larry Shiner en La invención del arte, parece obvio que la historia del arte es parte de un catálogo de productos epistemológicos consecuentes con las transformaciones económicas que se dan en Europa occidental durante esta etapa. Las dicotomías que citábamos anteriormente confraternizan con las nuevas lógicas de un mercado europeo en proceso de cambio. Tal vez por ello no esté fuera de lugar preguntarse si la práctica de la historia del arte, la disciplina en sí misma, responde a las necesidades políticas coetáneas a su origen. Preciado nos da algunas pistas, y el binomio cuerpo-imagen emerge de nuevo: Ios nuevos cuerpos disciplinados funcionan como fuerzas de reproducción nacional en el gran proceso político occidental de este período, la conformación de los Estados-Nación; la historia del arte, una vez más, tiene mucho que aportar al respecto.

En el capítulo «La amenaza fantasma: ¿La cultura visual como fin de la historia del arte?», Matthew Rampley sugería lo siguiente:

Donde la identificación nacional y cultural está tan estrechamente relacionada con un legado artístico específico, es difícil imaginar una situación en la que el auge de los medios trasnacionales de comunicación populares superará del todo la relación del arte con su historia (2005: 57).

Tomando como referencia la salud epistémica de la historia del arte en Gran Bretaña durante la segunda mitad del siglo XX, Rampley advierte que la aparición de los Es- 
tudios visuales en el panorama académico evidencia la inmunidad de la historia del arte en aquellos países en que la instrumentalización del patrimonio para la construcción de la identidad nacional está tan arraigada. El régimen disciplinario marca el paso de unas imágenes que, si antes eran la expresión de una soberanía irrevocablemente individual, ahora serán el testimonio de la riqueza de las naciones. Desde la segmentación del relato artístico en escuelas nacionales hasta la reivindicación de la visibilidad del patrimonio por parte focos geográficos menores, los métodos de la historia del arte han estado estrechamente imbricados con las formas de articular el relato nacional, a niveles macro y micro-narrativo, macro y micro-político. Aún hoy se reproducen estos protocolos, si bien las dificultades a la hora de amparar la fábula nacional cada vez son mayores y las imágenes se resignifican en un medio cultural transnacional.

Comprobamos de nuevo que el desarrollo de la historia del arte va de la mano de los procesos de mutación económico-política que se dan en las sociedades europeas de finales de siglo XVIII y principios del siglo XIX. Si acordamos que la evolución de la disciplina está estrechamente vinculada a determinados ejercicios del poder, podríamos elucubrar si sobre esta incide alguna de las premisas de la tecnología de gobierno que nace en este momento y Foucault examinó bajo el nombre de biopolítica. Sin titubeo nos preguntamos: ¿existe alguna relación entre la historia del arte y la biopolítica?

Explicando este nuevo régimen político, Castro-Gómez sostiene que

[...] la autoridad del soberano ya no se definía tanto por su capacidad de quitar o perdonar la vida de los súbditos que transgredían la ley, infringiendo castigos violentos en sus cuerpos, por el contrario, ahora se definía por la capacidad de producir la vida de sus súbditos, es decir, de generar unas condiciones sociales para que los cuerpos pudieran convertirse en herramientas de trabajo [...]. La biopolítica es, entonces, una tecnología de gobierno que intenta regular procesos vitales de la población [... y y que procura optimizar unas condiciones (sanitarias, económicas urbanas, laborales, familiares, policiales, etc.) que permitan a las personas tener una vida productiva al servicio del capital (2007: 156).

Es decir, la biopolítica es una nueva tecnología de gobierno fundamentada en la gestión minuciosa y vigilante de la vida de los individuos de la población. Con el fin de regular el papel de los mismos en tanto fuerzas de producción para beneficio del sistema económico, las nuevas dinámicas de saber/poder discurrirán por las instituciones -hospitales, cárceles, escuelas, etc.-, las cuales funcionan como nuevos contextos del circuito vital del individuo. La biopolítica surge, por tanto, a partir del minucioso proceso de sofisticación de los viejos sistemas de control y vigilancia social. El devenir biopolítico de las formas de gobierno modernas lleva implícito una serie de reajustes en las concepciones del espacio, el discurso y la subjetividad.

Esta nueva gramática del poder suele ser expresada a través de su metáfora arquitectónica más preciada: el panóptico que Jeremy Bentham diseñó en 1791. «Pido disculpas a los historiadores de la filosofía por esta afirmación, pero creo que Bentham es más importante, para nuestra sociedad, que Kant o Hegel» (Foucault, 2011: 103). En estos términos habla Foucault del creador de la que posiblemente sea la máquina tecnopolítica más importante de la modernidad. El panóptico constituye el gran archivo de la vigilancia contemporánea; una insólita ingeniería para una nueva mirada que se torna despersonalizada e inverificable (Foucault, 2002: 186). Los saberes y disciplinas que abren los ojos en este momento, por tanto, nacen en el seno de una nueva codificación de los sistemas gubernamentales; este novedoso, y así llamado, biopoder ${ }^{7}$ empapa el funcionamiento de las instituciones y justifica el cariz disciplinario de los discursos científicos.

¿Se ve afectada, por tanto, una incipiente historia del arte por esta metamorfosis de los mecanismos del poder? ¿Podemos aceptar que la disciplina aporta simplemente una mirada taxonómica y neutral hacia las imágenes una vez comprobado que nace en el epicentro de una política reguladora de la mirada y sistematización de las estrategias de subjetivación de la modernidad? ¿Funciona directamente como una táctica de normalización de las imágenes? ¿Oculta, en definitiva, la historia del arte un engranaje enraizado en lo biopolítico? Leamos el siguiente fragmento:

Si sabemos utilizar aquello que las Bellas Artes pueden ofrecer para llenar la imaginación de un hombre con la idea de lo Bello, y para volver a su corazón sensible a lo Bueno, se podrá hacer de ese hombre todo aquello en lo que su capacidad natural le permitirá convertirse. Para lograrlo bastará 
que el Filósofo, el Legislador, el Filántropo, ofrezcan al artista primero sus máximas, segundo sus leyes y por último sus proyectos. [...] que las artes penetren en la más humilde cabaña del más ínfimo ciudadano, es necesario que la tarea de dirigir su utilización y de determinar su uso entre en el sistema político, y sea uno de los objetivos primordiales de la administración del Estado [...] (Citado en Méndez, 2009: 21).

Estas líneas pertenecen a General Theory of Beautiful Arts, texto del filósofo suizo Johann Georg Sulzer (1720-1779). Varios fragmentos de este ensayo fueron incorporados como entradas sobre arte y estética en la Encyclopédie francesa. Con un influjo platónico innegable, las máximas del pasaje representan a la perfección el sentido moderno del arte y la función social del dispositivo artístico. El arte transmuta en herramienta para hacer que el ciudadano se vuelva «sensible a lo Bueno», por lo que resulta idóneo que se convierta en un asunto de Estado. Es totalmente conveniente, dictamina Sulzer, que las bellas artes formen parte de la programación política; el discurso jurídico en torno a las imágenes artistizadas se burocratiza como apéndice de la administración estatal: el texto visibiliza el devenir-sistema del arte.

Sulzer plantea el diseño teórico de una estructura que logre en «[cierto número de imágenes ${ }^{8}$ ] la impresión que se quiera producir, de cerciorarnos de sus movimientos, de sus reacciones, de todas las circunstancias de su vida, de modo que nada pudiera escapar ni entorpecer el efecto deseado.» Cambien «imágenes» por «hombres»: la cita está extraída de la descripción del Panóptico por parte de Bentham (1791).

El dispositivo artístico produce, por tanto, otro espacio de control fundamentado en una suerte de biopolítica de la mirada. La historia del arte formaliza el panóptico archivístico-discursivo de dicho dispositivo ${ }^{9}$. Lo que se viene a evidenciar es que, lejos de la visión despolitizada y estetizada que de ella aún se hace y que ella hace de sí misma, la historia del arte se enmarca en el centro de los fenómenos de producción de subjetividad y sentido dominante en Occidente. Por ello, representa un ejemplo paradigmático de narrativa que no tendría cabida sin la coyuntura ideológica y epistemológica que aflora en el escenario político de la Europa occidental en las postrimerías del siglo XVIII.

En definitiva, esta concepción de la disciplina abona el terreno para una nueva cosecha de hipótesis, todas conse- cuentes con la consideración de que «Arte» no es más que la ficción histórico-cultural resultante de lo que calificaríamos como régimen disciplinario de las imágenes en la modernidad, así como los conceptos «mujer» $u$ «homosexual» son las propias del régimen disciplinario y discurso moderno sobre el cuerpo y la subjetividad. La relación artística con las imágenes no es algo inherente ni al ser humano ni a estas en sí, tal y como ha tratado de naturalizar la agenda estética occidental, por lo que la historia del arte no es más que un capítulo, una suerte de sub-apartado de la historia de las imágenes, resultado de la compleja maquinaria racionalista propia de la llustración ${ }^{10}$. El siguiente fragmento de Gabriel Cabello nos ayuda a comprender esta hipótesis:

[...] la imagen no puede ser reducida a la obra de arte, que no puede reificarse en un objeto tangible e histórico que permita la clasificación, datación y exposición. [...] la imagen puede residir en la obra de arte, pero no coincide con ella: del mismo modo que existieron imágenes «antes del arte», las mismas que fueron excluidas de la narrativa moderna sobre el arte, hija del Renacimiento y de la Reforma, existirian imágenes "después del arte», es decir, después de la crisis del discurso moderno sobre la representación y su inherente iconoclastia. (2010: 34)

Por tanto, el dispositivo artístico -conglomerado de discursos, rituales, prácticas, instituciones y actitudes centradas en la inscripción y naturalización de lo artístico en las imágenes- se fundamenta en una ética biopolítica de la mirada que se adapta al nuevo régimen de visibilidad, de manera que nos aproximaríamos a Deleuze cuando definió el concepto de dispositivo como

[...] máquina para hacer ver y hacer hablar que funciona acoplada a determinados regímenes históricos de enunciación y visibilidad [que] distribuyen lo visible y lo invisible, lo enunciable y lo no enunciable al hacer nacer o desaparecer el objeto que, de tal forma, no existe fuera de ellos (Citado en García, 2011: 4).

La historia del arte es el archivo discursivo de dicho régimen. En última instancia, es el panóptico particular del arte, entendiendo este como máquina de producción y distribución de lo visible, lo decible y lo representable para se- 
gún qué imágenes; la disciplina construye la arquitectura discursiva que garantiza el funcionamiento de la nueva vigilancia hacia las imágenes y la inclusión de las mismas en un perímetro disciplinario insólito hasta entonces. «Para que haya arte, [solo] hace falta una mirada y un pensamiento que lo identifique» (Rancière, 2004: 15). Contra quienes la acatan como un saber neutro, científico y puramente taxonómico, la historia del arte es la tecnología disciplinaria resultante de un nuevo orden político, y sus estrategias, procedimientos y protocolos tienen que ver con una biopolítica de la mirada, una compleja y discreta administración de los sentimientos apropiados entre cuerpos e imágenes ${ }^{11}$.

\section{Notas}

1 Las referencias de Preciado están extraídas del seminario Cuerpo impropio. Guía de modelos somatopolíticos y de sus posibles usos desviados, que impartió y dirigió en 2011 en la Universidad Internacional de Andalucía. Se adjunta un enlace al resumen de las sesiones que ofrece la propia institución organizadora. En: <http://ayp.unia.es/index.php?option=com_content\&task=view\&id=703> (fecha de consulta: 21-07-2019).

2 Preciado alude a un tercer y último régimen somatopolítico, pero las hipótesis del artículo se ubican en la transición de los dos descritos.

3 «Nos enfrentamos diariamente a dispositivos de poder y técnicas de producción del cuerpo y de la subjetividad que están ligados a diferentes paradigmas epistemológicos. Paradigmas entre los que se producen tensiones y conflictos, pero entre los que también se establecen solapamientos de diversa índole y relaciones de alianza estratégica». En: <http://ayp.unia.es/index.php?option=com_content\&task=view\&id=703> (fecha de consulta: 21-07-2019).

4 Judith Butler afirma: «Foucault continúa entonces mostrando que el saber y el poder finalmente no son separables, sino que operan juntos para establecer una serie de criterios sutiles y explícitos para pensar el mundo» (2008: 160).

5 Y redundamos en lo de «determinadas», pues, como han demostrado los estudios de Didi-Huberman, Belting, Bredekamp o Freedberg, por citar los más célebres, existe un amplio espectro de imágenes y objetos que quedan «bajo la sombra del discurso del arte» (Belting, 2007: 22), evidenciando así la dimensión radical y arbitrariamente excluyente de la disciplina.

6 «Este libro desearía, simplemente, interrogar acerca del tono de certeza que reina en la bella disciplina de la historia del arte. Debería resultar evidente que el elemento de la historia, su fragilidad inherente frente a todo procedimiento de verificación, su carácter extremadamente lagunoso, en particular en el campo de los objetos figurativos fabricados por el hombre, resulta evidente que todo esto debería incitar a una mayor modestia".

7 «El concepto de biopoder fue utilizado y desarrollado por Foucault para referirse a la sociedad disciplinaria, determinada por el interés de ejercer poder sobre la vida y la productividad humana a través de la regulación social gubernamental y sus dispositivos de vigilancia, seguridad, análisis y gestión. El biopoder es una rama de poder que aspira a controlar la vida humana» (Mariblanca, 2016: 42).

8 La cursiva es propia.

9 «En este sentido, el Panóptico es un aparato arquitectónico para poner en práctica la lógica discursiva del gráfico, la tabla, el diagrama, la lista taxonómica o el teatro mnemotécnico del conocimiento -en resumen, toda la parafernalia de las ciencias humanas y naturales» (Preziosi, 1989: 64).

10 En este sentido, Hal Foster destaca los dos pilares filosóficos sobre los que pivota el nacimiento de la historia del arte: por un lado, la premisa kantiana de la autonomía del objeto artístico; por otro, el «modelo filosófico de la historia hegeliana» (2004: 85).

11 «Crees que te acercas al arte voluntariamente, atraído por su belleza, que esta relación se desarrolla en una atmósfera de libertad y que en ti nace el placer espontáneamente surgido de la divina varita mágica de la Belleza. Lo que ocurre en realidad es que una mano te ha agarrado por el cogote, te ha conducido ante el cuadro y te ha puesto de rodillas, y que una voluntad más poderosa que la tuya te ha mandado esforzarte para que experimentes sentimientos apropiados" (Wombrowicz, 2017: 47).

\section{Bibliografía}

BELTING, Hans (2007), Antropología de la imagen, Katz Editores, Buenos Aires.

BENAVIDES FRANCO, Tulio Alexander (2017), «El cuerpo como espacialidad ambigua: Somato-política y resistencias corporales en Michel Foucault», Daimon Revista Internacional de Filosofía, Suplemento 5, pp. 601-610.

BUTLER, Judith (2008), «¿Qué es la crítica? Un ensayo sobre la virtud de Foucault», en Producción cultural y prácticas instituyentes. Líneas de ruptura en la crítica institucional, Transform, Traficantes de sueños, Madrid, pp. 141-167.

CABELLO PADIAL, Gabriel (2010), «Malestar en la historia del arte: sobre la antropología de las imágenes de Hans Belting y Georges Didi-Huberman», Imago Crítica, n. ${ }^{\circ}$ 2, pp. 29-52.

CASTRO-GÓMEZ, Santiago (2007), «Michel Foucault y la colonialidad del poder», Tabula Rasa, n. 6, enero-junio, pp. $153-172$. CRIMP, Douglas (2005), Posiciones críticas. Ensayos sobre las políticas de arte y la identidad, Akal, Madrid.

DIDI-HUBERMAN, Georges (1990), Ante la imagen. Historia del arte y anacronismo de las imágenes, Adriana Hidalgo editora, Buenos Aires. 
DIDI-HUBERMAN, Georges (2017), «Leer, una y otra vez, lo que nunca ha estado escrito», en CABELLO PADIAL, Gabriel, LESMES, Daniel, MASSÓ CASTILLA, Jordi (coords.), Georges Didi-Huberman. Imágenes, historia, pensamiento, Anthropos. Cuadernos de cultura crítica y conocimiento, n. ${ }^{\circ} 246$, pp. 113-132.

FOSTER, Hal (2004), Diseño y delito, Akal, Madrid.

FOUCAULT, Michel (1991), La arqueología del saber, Siglo XXI, México D. F.

- (2006), Las palabras y las cosas. Una arqueología de las ciencias humanas, Siglo XXI Editores, Madrid.

- (2011), La verdad y sus formas jurídicas, Editorial Gedisa, Barcelona.

- (2002), Vigilar y castigar. Nacimiento de la prisión, Siglo XXI, Buenos Aires.

GARCÍA FANLO, Luis (2011), «¿Qué es un dispositivo?: Foucault, Deleuze, Agamben», A Parte Rei: Revista de filosofía, n. ${ }^{\circ}$ 74, marzo, pp. 1-8. HANTELMANN, Dorothea Von (2017), Cómo hacer cosas con arte, Consonni, Bilbao.

LÓPEZ RUBIÑO, David (2015), Institución y naturalización del arte. La ideología del arte universal y el legado artístico como una colección de Ready Mades, Universidad de Granada, Granada.

MARIBLANCA CORRALES, Pedro José (2016), Tiqqun y la cuestión del Bloom, Brumaria, Madrid.

MÉNDEZ, Lourdes (1999), Antropología del campo artístico: del arte primitivo al contemporáneo, Síntesis, Madrid.

ORTIZ MALDONADO, Natalia (2009), «Crítica y brujería. Apuntes para desestabilizar el presente». Caja Digital. Tomás Abraham. En: <http:// tomasabraham.com.ar/index.php/31-caja-digital/caja-2009/245-la-produccion-filosofica-intelectual-y-de-pensamiento-del-tercer-milenio> (fecha de consulta: 20-07-2019).

PRECIADO, Paul B. (2011, noviembre), «Genealogía somatopolítica y marcos de inteligibilidad corporal: del cuerpo soberano al cuerpo biopolítico", en Cuerpo Impropio. Guía de modelos somatopolíticos y de sus posibles usos desviados. Universidad Internacional de Andalucía. Sevilla. En: <http://ayp.unia.es/index.php?option=com_content\&task=view\&id=703> (fecha de consulta: 21-07-2019).

- (2008), Testo Yonki, Espasa Calpe, Madrid.

PREZIOSI, Donald (1989), Rethinking Art History: meditations on a coy science. Yale University Press, New Haven and London.

RAMPLEY, Matthew (2005), «La amenaza fantasma: ¿La cultura visual como fin de la historia del arte?», en BREA, José Luis (coord.), Estudios visuales: la epistemología de la visualidad en la era de la globalización, Akal, Madrid, pp. 39-57.

RANCIÈRE, Jacques (2004), Malaise dans l'esthétique, Galilée, París.

SHINER, Larry (2014), La invención del arte: una historia cultural, Paidós, Barcelona.

WOMBROWICZ, Witold (2002), Ferdydurke, Seix Barral, Barcelona.

- (2017), Diario (1953-1969), El cuenco de plata, Buenos Aires. 